\title{
Does Facility Based Sexual and Reproductive Health Services Meet the Needs of Young Persons? Views from Cross Section of Ghanaian Youth
}

\author{
Jonathan Mensah Dapaah1, Seth Christopher Yaw Appiah ${ }^{1 *}$ Eric Badu², Bernard Obeng1, \\ Victoria Ampiah ${ }^{1}$ \\ ${ }^{1}$ Department of Sociology and Social Work, Faculty of Social Sciences, Kwame Nkrumah University of Science \\ and Technology, Kumasi, Ghana \\ ${ }^{2}$ Department of Community Health, School of Medical Sciences, Kwame Nkrumah University of Science and \\ Technology, Kumasi, Ghana \\ Email: ${ }^{*}$ Sychrist2007@Gmail.com
}

Received 8 June 2015; accepted 26 July 2015; published 29 July 2015

Copyright $@ 2015$ by authors and Scientific Research Publishing Inc.

This work is licensed under the Creative Commons Attribution International License (CC BY).

http://creativecommons.org/licenses/by/4.0/

\section{c) (i) Open Access}

\begin{abstract}
The focus on facility based health setting to provide sexual and reproductive health to the youth has been tested in several settings and achieved varying results. This study examined whether facility based sexual and reproductive health services met the needs of Ghanaian youth. Adopting the descriptive cross sectional design, 170 youths between the ages of 10 and 24 were sampled. A three-stage stratified random sampling technique was adopted. The results of the study are presented using descriptive statistics. The study established that a total of $55.8 \%(95 / 170)$ of the youth had utilized at least one or more of a sexual and reproductive health service in life time. However, only 45.2\% (43/95) of youth used or accessed sexual and reproductive health services from a facility based setting. Facility based sexual and reproductive health service provided specifically for the youth is very limited. This calls for the provision of out-of health facility services located within the communities and at strategic places while ensuring confidentiality to the youth. More rigorous research is recommended on a national scale to examine youth preference for the type of facility based and out-of-facility based sexual and reproductive health services to meet the needs of young people.
\end{abstract}

\section{Keywords}

Facility-Based, Sexual and Reproductive Health, Young Persons, Youth, Needs, Ghana

"Corresponding author.

How to cite this paper: Dapaah, J.M., Appiah, S.C.Y., Badu, E., Obeng, B. and Ampiah, V. (2015) Does Facility Based Sexual and Reproductive Health Services Meet the Needs of Young Persons? Views from Cross Section of Ghanaian Youth. Advances in Sexual Medicine, 5, 61-71. http://dx.doi.org/10.4236/asm.2015.53008 


\section{Introduction}

The sensitive nature of discussing sexual and reproductive health matters in Ghana especially among young people makes service utilization difficult. Notwithstanding the difficulty in having such public discourse, improving sexual and reproductive health service utilization among young persons is significant for both economic and public health benefit to a country [1]. The sexual and reproductive health challenges that the youth face range from early marriage and child bearing, STIs and HIV which derail a nation's socioeconomic development.

A variant of issues emerge when it comes to the utilization of sexual and reproductive health services by the youth in health facility settings. Key among such factors is the attitude of health care providers. Studies by Katz and Naré [2], Erulkar and colleagues [3] in Senegal, Kenya and Zimbabwe respectively have identified fear as a major barrier to seeking sexual and reproductive health care in facility settings among youth. To young persons, the fear of being seen to be accessing sexual and reproductive health service made them feel ashamed about their needs. This is coupled with the negative attitudes of service providers, lack of privacy and confidentiality, and age restrictions. Thus facility related factors continue to pose a challenge to achieve the objective for establishing such sexual and reproductive health service giving facility.

Many countries employ recreational facilities as tools for providing sexual and reproductive health education to young people [4]. This has been done through empowering young persons in making sexual decisions through new skill learning. Despite the global dimension of these interventions, the success stories are mixed, without any consensus in the body of literature on the effectiveness of these interventions [5] [6].

Cost and programme ineffectiveness are mostly cited as the challenges to facility based sexual and reproductive health interventions [6] [7] (Ross, 2010). There is often the question of limitedness in evaluation designs for interventions in the Sub-Saharan region. A few evaluations on sexual and reproductive health have reported ability of such interventions to reduce risky sexual behaviours and resulting HIV and STIs [8].

Youth friendly reproductive health services influences service utilization positively [8]. It is widely acknowledged among reproductive service health providers throughout the world that "Youth Friendly" services are needed if the youth are to be adequately provided with reproductive health care [5] [9]-[11]. The demand for youth friendly services is informed by its ability to effectively attract the youths, meet their needs comfortably and responsively, and succeed in retaining these young clients for continuing care. These services should however be characterized by specially trained providers, privacy, confidentiality and accessibility to the youths [12]. However, youth generally do not see health as an issue of need of services [13] and that may access sexual and reproductive health service only when a sexual action has the tendency of causing danger, harm or discomfort to the youth. Brindis and Davis [14] indicated that the needed health service delivery that would be friendly to the youth should include the features as sexual and reproductive health education and counseling, physical examinations, cervical cancer screening and the STD screening, counseling, and treatment, HIV testing and counseling and others. There is a need for services that emphasize meeting the needs of young people in a variety of places where they congregate which includes malls, bus parks, the streets, recreational centres and sporting events [15]. This means bringing health services to the door step of the youths.

In the study of Zabin \& Clark [16] in the USA, young people notably, virgins or those within two months of having had their first intercourse were more likely to enroll in a clinic with special teens hours rather than those which offered equal care for all people and not only the youth. Similar findings were made in Jamaica where clinics with special teen hours or solely made for addressing the health needs of the youth received much attendance by the youth [17]. This reiterates the need for separate services provided to the youth, to overcome their resistance to access the traditional health care system [18]. Though youth only facility-based sexual and reproductive health service has been documented to receive youth participation and service utilization [16]-[18], the youth continue to request out-of-facility sexual and reproductive health services [19].

In Ghana there are situations where youth have shown interest in facility based sexual and reproductive health services and reported friendliness of service though separate services were not created for them. Evidences exist in Ghana where youth who have shown interest in service have a difficulty locating where sexual and reproductive health services are located [20].

There is a component of reproductive health services that are out of health-facility based. These types of services are offered in homes by family members, older peers in community, outreach youth reproductive health services delivery by health education promoters, church and mosque leaders at religious meetings. The pivot of the services rendered to the youth is one that is acceptable, appropriate and accessible. In-school sexual and reproductive health services are essential component of out-of health facility services. In-school interventions 
benefit from a ready-made audience and there is reasonably strong evidence of the benefits of using curriculumbased participatory and life skills approaches to increase knowledge and awareness [19]. Significant increase in condom use, knowledge of STDs and reduction in sexually transmitted disease symptoms as a result of Inschool interventions has been reported in Nigeria when active referral systems between schools and health facilities were evaluated using a Randomized Controlled Trial (RCT) [21]. Earlier evidence of a quasi-experimental evaluation of an out-of-facility based intervention using a matched control did not establish any significant impact on reproductive health service use [22]. The evidence of the study was weakened on the basis that the schools and clinics chosen were chosen in part due to their willingness to participate. In addition the "before and after" groups differed due to high drop-out. The study did not account for the drop out reasons with the logistic regression only controlling for chosen variables. Other factors that correlated with the outcomes of interest may therefore exist [22].

Such weakness limited the out-of-facility sexual and reproductive health interventions ability to improve service use among the youth. Michielsen et al. [23] have argued however that, school based sexual and reproductive health interventions decline in their effectiveness over time resulting from broader intervention, limitedness in methodologies and overemphasis on increasing knowledge which has been found cannot alone change sexual behavior of youth [24]-[26].

In Bangladesh, Kenya, Mexico and Senegal, applying quasi-experimental intervention design to test the effect of in-school education in addition to that of community mobilization activities and youth friendly health services, the study did not demonstrate a consistent pattern of improvement in sexual and reproductive health service through out-of-facility based interventions between the countries. No impact on service use was found in Mexico and Kenya [27], while in Bangladesh service use doubled in the intervention area without the school component, and increased ten-fold when it was included, but no significance testing was carried out. In Senegal a significant increase $(p<0.05)$ above the control was only found when the school intervention was included. The implication of this finding was that, where there was an observation of an increase in service utilization, it was due to the out-of-facility intervention [28] [29].

Youth sexual and reproductive health activities led by other organizations were going on in both control and intervention areas [30]-[33]. Evidence suggests however that, sessions of youth within the community struggled to maintain attendance over a period of time, with other commitments often getting in the way [23] [34]. This calls for an integrative service approach to increase service uptake.

The combined provision of services through the use of peer education, recreational activities and media yielded some results in three separate interventions as reported in Dushishoze [35], Pathfinder International in Gweru [36] and ABTEF youth centre in Togo [37]. In Rwanda, Zimbabwe and Togo clinic data which were reviewed over time did not have any control. No significant effect was found between youth centre visitation and reproductive health service utilization in Zimbabwe.

Hessburg et al. [1] posited that providing either out-of health facility sexual or reproduction health service in stand-alone to Ghanaian youth or whether to continue with facility base reproductive health services put service providers in between two fix areas amidst logistical and monetary constraints. Despite the existence of theoretical and empirical knowledge about sexual and reproductive health provided by health facilities, studies are inconsistent [38]. Family Health International and many assumptions remain unaddressed. Currently empirically based evidence to show how effective an investment into out-of-facility based sexual and reproductive health service will be is non-existent in Ghana. Whether the existing facility based sexual and reproductive health services centers are meeting the needs of young people constitutes the objective of this study.

\section{Methods}

\subsection{Study Area}

The study location was the Kwadaso Sub metro district of the Ashanti region of Ghana. It is found within the Kumasi metropolis. The Kumasi metropolis is located in the forest zone and council forms part of the nine administrative sub metro councils of the Kumasi metropolis. The total population of all persons in the Kwadaso sub metro district council is 220,798 [39] (GSS, 2010).

The Sub Metro has one Town Council that serves its nine electoral areas with 25 Councilors.

The Sub metro is home to key of Ashanti regions hospitals and health services centres which include the Seventh Day Adventist hospital (SDA), Siloam Hospital-Kwadaso, Maranatha Hospital, Dr. Amin Bonsu Hospital, Marie Stoppes International Center and Apatrapa Maternity Ward. The Sub Metro has fifty-nine (59) schools 
including twenty (20) Junior High Schools, two secondary schools and five tertiary institutions.

\subsection{Study Design and Sampling}

This study employed a cross-sectional with multistage sampling design in selecting 170 youth aged $10-24$. The sampling frame consists of a list of elements (units) of the population. The sample frame constituted all youth aged 10 - 24 in the study area. The sample frame was 84,083 [39] (GSS, 2010). In Stage 1, one administrative region, the Ashanti region was selected randomly from ten regions across Ghana which is differentiated by regional location. The stage 2 involved the selection of one district; Kumasi metropolis from the 30 districts in the Ashanti region. In the Stage 3, the Kwadaso Sub metro council was randomly selected from nine (9) sub metro councils. The cluster stratified sampling was used to categorize the youth into two main strata; out-of-school youth and in-school youth. The in-school youth were further clustered along three cohorts of junior high school youth, senior high school youth and tertiary students which were selected randomly basing on the closeness to the main hospital in the study area.

The study location was clustered into four areas (Sofoline, Market area, Agric Nzema and Asuoyeboa area) from within which 20 out-of school youth were sampled randomly selected from to conduct the study. After the stratified sampling had been adopted in grouping the students according to their classes in their school, random sampling was employed in collecting data from the youth from within each stratum. Out-of school youth were interviewed using structured questionnaires on one-on-one schedule. The focus of the questions was on sociodemographic characteristics and issues of facility based sexual and reproductive health service utilizetion. The Socio-demographic information consisted of, age, gender, occupation, education, religion and. Questions on utilization of facility based sexual and reproductive health services related to the type of services ever accessed, intention for subsequent visit or otherwise and the reasons for the decision to revisit service centres or not.

\subsection{Data Collection}

The study administered questionnaires to the in-school youth and structured interviews to collect information from out-of-school. The questionnaire were prepared in English and given out to the in-school youth. The questionnaire was pre-tested at a mixed sex secondary school; Elite College. The interviews were conducted in Asante Twi, the local language of majority of the residents. Out-of-school youth were interviewed using structured questionnaires on one-on-one schedule. The focus of the questions was on socio-demographic characteristics and issues of facility based sexual and reproductive health service utilization. The Socio-demographic information consisted of, age, gender, occupation, education, religion and. Questions on utilization of facility based sexual and reproductive health services related to the type of services ever accessed, intention for subsequent visit or otherwise and the reasons for the decision to revisit service centres or not. The response rate was $94.4 \%$.

\subsection{Data Analysis}

The results were generated using descriptive statistics. The data analysis involved the estimation of percentage of the responses of the respondents. The distribution of factors pertaining to the utilization of facility based sexual and reproductive health service, type of service used, sexual experience of youth and reason for subsequent visit or not was estimated using percentages and frequency Thus, the univariate analysis (T2, T3, T4), comprise of a frequency distribution of selected variables which are pivotal to this study.

\subsection{Ethical Consideration}

Ethical Clearance was sought form the Department of Sociology and Social welfare. More to that, both written and verbal consent were sought from the school heads and participants whiles assuring them of the highest level of anonymity and confidentiality.

\section{Results}

The results of the study are presented on the 170 youth who were surveyed. This section presents results from the cross tabulation (Table 1) and univariate (Tables 2-4).

From Table 1, 25.3\% (38/150) in-school youth had ever used sexual and reproductive health service (SRHS) 
Table 1. In-school youth utilization of facility-based sexual reproductive health service before* level of education.

\begin{tabular}{cccccc}
\hline \multirow{2}{*}{ Variable } & & \multicolumn{3}{c}{ Level of education of youth } & Total \\
\cline { 3 - 5 } & & Tertiary & Secondary & Junior High School & \\
\hline $\begin{array}{c}\text { Whether youth has ever used } \\
\text { facility-based reproductive } \\
\text { health Service }\end{array}$ & Yes & 15 & 16 & 7 & $\mathbf{3 8}(\mathbf{2 5 . 3 \% )}$ \\
Total & No & 32 & 32 & 36 & $\mathbf{1 0 0}(\mathbf{6 6 . 7 \% )})$ \\
\hline
\end{tabular}

"Estimates not 100\%, since not all in-school youth responded.

Table 2. Sexual experience and facility based sexual and reproductive health services.

\begin{tabular}{|c|c|c|}
\hline Variable & $\mathbf{N}$ & $\%$ \\
\hline \multicolumn{3}{|c|}{ Facility based sexual reproductive health services utilized by in-school youth in lifetime } \\
\hline o Contraceptives & 9 & 23.9 \\
\hline o Condoms & 17 & 44.6 \\
\hline o Sexual and reproductive counselling & 12 & 31.5 \\
\hline Total & 38 & 100 \\
\hline \multicolumn{3}{|l|}{ Sexual experience among youth of all youth category } \\
\hline o Yes & 77 & 45.2 \\
\hline o No & 93 & 54.8 \\
\hline Total & 170 & 100 \\
\hline \multicolumn{3}{|l|}{ Utilisation of FBSRHS by youth (All youth categories, $N=170$ ) } \\
\hline \multicolumn{3}{|l|}{ Yes } \\
\hline - In-school youth $(N=\mathbf{1 5 0})$ & 38 & 25.3 \\
\hline - Out of school youth $(\boldsymbol{N}=\mathbf{2 0})$ & 5 & 25 \\
\hline Total & 43 & 25.2 \\
\hline \multicolumn{3}{|l|}{ No } \\
\hline - In-school youth & 100 & 66.7 \\
\hline - Out-of school youth & 15 & 75 \\
\hline - Not applicable responses & 12 & 8 \\
\hline Total & 126 & 74.2 \\
\hline Total utilisation for all youth category & 43 & 25.2 \\
\hline \multicolumn{3}{|c|}{$\begin{array}{l}\text { Reasons why in-school youth did not use facility-based sexual reproductive health service until after first sexual } \\
\text { experience }\end{array}$} \\
\hline o Ignorance & 8 & 23.5 \\
\hline o Lack of service & 7 & 20.6 \\
\hline o Lack of motivation by others & 7 & 20.6 \\
\hline o Fear of stigmatization from society & 0 & 0 \\
\hline o Fear of parents & 12 & 35.3 \\
\hline Total & 34 & 100.0 \\
\hline \multicolumn{3}{|c|}{ Reproductive health service utilized by in-school youth during visit to the hospital/clinic in the last six months } \\
\hline o Treatment for STIs infection & 10 & 33.3 \\
\hline o Family planning & 5 & 16.6 \\
\hline o Counselling & 13 & 43.3 \\
\hline o Abortion and pregnant & 2 & 6.6 \\
\hline Total & 30 & 100 \\
\hline
\end{tabular}

at the facility. Not all in-school youth expressed their opinion on their use of SRHS. 92\% (138) of youth responded to the questions of ever using SRHS. Out of the remaining 12 (8\%) young persons who declined to respond to the question of ever using facility-based SRHS, three (3), two (2) and seven were in tertiary, secondary and junior high school levels respectively. Majority 66.6\% (100/150) of In-school youth have never used facility-based SRHS. 15 out of the 38 youths who had ever used SRHS were in the tertiary institution, 16 were in secondary schools while 7 were in the Junior High school. This implies that the youths in the secondary schools utilize reproductive health services more than the rest of the youth. 
Table 3. Facility based sexual reproductive health service utilization related factors.

\begin{tabular}{lr}
\hline \multicolumn{1}{c}{ Factor } & $\mathbf{N}$ \\
\hline $\begin{array}{l}\text { Whether in-school youth are aware of any facility-based youth friendly sexual reproductive health services offered } \\
\text { to youth in the district }\end{array}$ & 41 \\
o Yes & 27.3 \\
O No & 109 \\
Total & 72.7 \\
Whether youth (all categories) will visit SRHS centre visited last time for Sexual reproductive health services. & 100 \\
O Yes & 37 \\
O No & 58 \\
Total & $\mathbf{1 5 0}$ \\
\hline
\end{tabular}

Table 4. Reason for youth non-visit or subsequent visit to access FBSRHS.

\begin{tabular}{|c|c|c|c|}
\hline & Reason for youth intention to revisit youth centre/hospital/counseling/sick bay & $\mathbf{N}$ & $\%$ \\
\hline 0 & Friendly, caring staff & 13 & 35.1 \\
\hline 0 & Short waiting time & 6 & 16.2 \\
\hline 0 & Youth corner & 5 & 13.5 \\
\hline 0 & Place to talk with peer counselors & 3 & 8.1 \\
\hline 0 & Convenience & 4 & 10.8 \\
\hline 0 & Had a nice experience & 6 & 16.2 \\
\hline \multicolumn{2}{|c|}{ Total } & 37 & 100 \\
\hline \multicolumn{4}{|c|}{$\begin{array}{l}\text { Why youth will not return to health facility/hospital/peer counselor/sick bay visited last time for sexual } \\
\text { reproductive health services again }\end{array}$} \\
\hline 0 & Needs parent permission & 29 & 50.0 \\
\hline 0 & Needed partner's permission & 13 & 22.4 \\
\hline 0 & Unfriendly staff & 6 & 10.4 \\
\hline 0 & Staff does not welcome/approve of young people & 10 & 17.2 \\
\hline \multicolumn{2}{|c|}{ Total } & 58 & 100 \\
\hline
\end{tabular}

Table 2 summarizes the number of youths and how they utilized facility based sexual reproductive health services mentioned.

From the results in Table 2, 23.9\% (9/38) of the in-school youth who had ever used FBSRHS utilized contraceptives, $44.6 \%$ (17/38) utilized condoms whiles 31.5\% (12/38) utilized sexual and reproductive health counseling. The interview with the out-of school youth showed that only two in the unaffiliated category had gone to a clinic to access facility based sexual and reproductive health services on the specific problem of menstrual difficulty, while three in affiliated youth category had ever accessed service.

Out of the entire youth studied who had had sexual encounter in life time before, 58.8\% (43/77) of them said they used FBSRHS after their first sexual experience. The services used under consideration were facility based sexual reproductive health services. The results show that out of 43 youth who utilized SRHS, a total of nine used sexual and reproductive service before first sexual experience (four In-school youth and five out-of-school youth). According to 35.3\% (12/30) of the youth, they did not use facility based sexual and reproductive health service before first sexual intercourse.

The study found that, 23.5\% of young persons utilized SRHS lately as a result of ignorance, 20.6\% youth on the other hand accessed service later due to the unavailability of SRH services during the first sexual initiation and among $20.6 \%$ of young persons, the lack of motivation by others denied them the ability to use sexual reproductive health service before their first sexual intercourse. The majority 10 youth who used SRHS after their first sexual experience offered other varied reasons why they did not use SRHS prior to first sexual experience. The reasons included not being interested, no specific reason and not grown up by the time of first sexual intercourse.

Table 2 show that, majority (43.3\%) went for counseling as the sexual and reproductive health services uti- 
lized during visit to the hospital or clinic during the last six months. To them the counseling services were friendly. The youth who sought treatment for STIs were $33.3 \%$ family planning was also given by $16.6 \%$ of the youth studied. Furthermore $6.6 \%$ of the subjects indicated they were at the hospital or clinic for abortion and pregnancy related issues.

Table 3 presents the responses from youth on whether they are aware of any youth friendly reproductive health service rendered to them in the area. The percentage of in-school youth who were not aware of such services in the area was high $72.7 \%$ (109/150).

The percentage of in-school youth who were aware of YFRHS rendered to them in the area was very minimal 27.3\% (41/150) constituting less than a third of the in-school youth. 80\% representing Sixteen (16) out of the twenty out-of-school youth interviewed corroborated the point of view of the in-school youth that they do not know of any youth friendly sexual reproductive health service facility in the area. Only four were in the known of the availability of such services in the study area. Additionally, the youth were made to assess whether they will go to the particular sexual reproductive health service provider again.

The study found that out of the total number of 95 youth who had used at least one or more sexual reproductive health in lifetime, majority $61.10 \%$ would not revisit where they accessed services whereas $38.9 \%$ would visit their reproductive health service provider again whether in facility or out-of-facility. The results show that whiles only $45.2 \%$ (43/95) both in-school and out-of school had used facility based (Clinics, hospitals, youth centers etc.) reproductive health services before, the total number of youth who had used both facility based and non-facility based sexual reproductive health services was more than half of the study population 55.8.\% $(95 / 170)$. The youth who use non-facility based sexual and reproductive health services were relatively higher $(30.5 \%, 52)$ than those who use facility based sexual reproductive health service $(25.2 \%, 43)$.

The results presented in Table 4 accounts for the reasons for young person's intention to revisit service providers or not to revisit.

The youth gave reasons such as caring staff (35.1\%), waiting time and having had a nice experience (16.2\%) as the reasons for revisit. Additionally, a percentage of 13.5 each said they would visit the same facility again because of the youth corner whiles to $8.1 \%$ of young persons the facility offers a place to talk with peer counselor. The studied found out that other factors such as waiting time (16.2\%) and convenience as reasons for revisit.

Among the 58 youth who were not in the position to revisit the service centre accessed in their previous time, (50\%) would need their parents' permission, $22.2 \%$ needed their partner's permission. According to $17.2 \%$ of the youth, the staff do not welcome or approve of young people accessing services and as such would not revisit the service centre again.

Others opined that unfriendly nature of the staff at the facility (10.4\%) accounted for their decision not to visit the centre subsequently.

\section{Discussion}

This study examines young person's perspectives on utilizing sexual and reproductive health services at facility level. We used cross-sectional survey design with multistage sampling to elicit information from affiliated and unaffiliated youth aged between 10 and 24. The study identified sexual and reproductive health service at the facility level was very minimal.

The study showed that a greater number of the youth who met their peer counsellor indicated that their peer counsellors were friendly. Some even went the extra mile to stipulate that their counsellors were very friendly. Family Health International [38] accords to the essence of peer counselling; holding that it is the most effective component of providing youth friendly reproductive health services. Population Council [40] reports that though greater number of the youth in the study accessed counselling; the benefits accrued to the educators themselves and not to the youths; thus, counselling in itself is not of any vital importance to the youths. This runs contrary to the view shared by the Family Health International [38]. In the present study, though contraceptive has mostly been used by In-school youth in their life time, sexual and reproductive health counselling was identified as the single most frequent accessed facility based sexual and reproductive health service among the youth during the last six months preceding the conduct of the study.

Despite the Pathfinder International [36] [37] recognizing youth friendly reproductive health services as appropriate and effective strategy for addressing the sexual and reproductive Health needs of the youth, majority of the youth sampled in this study have not visited either hospital or clinic for reproductive health services for the last six months. This shows the need to access youth friendly reproductive health services at hospitals or clinic 
has not been recognised by most youth in the present study area. The reason for the lower turn-in for accessing health services could be in line with Senderowitz and others [34] finding that the essence of accessing reproductive health services are because of specific biological and psychological needs of the youth, the high risks of STIs, HIV, and pregnancy, disproportionately high risk of sexual abuse, importance of behaviour related risks which are all subjectively related to every youth. In this study, parental and partners permission have been found to be determinants in youth subsequent visit to health centre.

Among the few who visited the health facilities; they indicated counselling as the major reason for the visit; followed by treatment for STIs infection, family planning and abortion and pregnancy respectively. Most of these youth spoke to doctors instead of Nurses, Health Assistant or counsellor about their sexual and reproductive health services and were very satisfied with the attitude of the staff and the nature of the services they received [5] [9]. The youth however indicated parental permission as the major reason why they are not likely to return to the health facility to accessed reproductive health services. This could be as a result of parental fear which influence the youths not to access reproductive health services in successive manner [13].

The issue of youth drop out and subsequent service use is common even among areas where interventions have been set up [22]. The study found that about a third of the youth (61.05\%) were not in the position to revisit where they accessed sexual and reproductive health service during their last visit.

The drop out in service utilization is consistent with Magnani [22] study, though he did not account for the reason for the youth intention not to revisit, this study found several interrelated factors to be responsible youth intention not to revisit. Corroborating Godia [41] study, the absence of a proper appreciation for the importance of sexual health care especially among parents could prevent youth from utilizing reproductive health service in consecutive manner. Additionally, the reproductive health challenge that accounted for youth visit to the service centre might have been addressed for which might have influenced youth decision not to revisit.

The youth indicated greater satisfaction for services they received from the health providers. In contrast and was inconsistent with earlier works by Pathfinder [42], that the attitude of service providers could be bad; however results in this study indicate otherwise. This finding confirms similar studies by Liu and others [11] study in China. However, despite youth satisfaction with service providers, only a quarter of the youth who had ever used sexual and reproductive health service had intention to revisit service point as against close to one third of them who decline willingness to visit subsequently.

Knowledge of the existence of facility base sexual and reproductive health service has been identified to be very low in this study. Only 25\% of all youth had ever accessed facility based sexual and reproductive health service in the study area out of the $58.2 \%$ of the youth who had ever utilized SRHS, with the majority $30.5 \%$, accessing service out-of health facility and not at facility level?

Whiles evidence by some scholars like Senderowitz, Michielsen and his colleagues [23] [34], suggest that youth attendance to out-of-facility based sexual reproductive may decline over a period of time, due to young person's commitments to other activities, the present study found contrary as the most preferred sources of sexual and reproductive health service utilization was mainly out-of-facility-based.

\section{Conclusions}

The study has established that despite the satisfaction of young persons with the sexual and reproductive services offered in the Kwadaso Sub metro council, service utilization was generally poor. This was partly attributable to the fact that majority of the youth did not know the existence of facility based sexual and reproductive health service despite their existence in the study area. The greater proportion of the youth had accessed services out of health facility.

Intention to revisit point of service delivery was generally on the low side. There is a need for services that integrate both out-of-facility and facility based sexual and reproductive health services. Additional sensitization campaigns are to be vigorously pursued to help young person's locate where facility based sexual and reproductive health service centres are located. In respect of policy interventions, the study finding offers an empirical base for training non health workers in the delivery of sexual and reproductive health services so that medical conditions could be referred to health facilities.

\section{Limitation of the Study}

The major limitation of this study was the issue of recall biases. The nature of the study required youth to give 
answers to events that had taken place in the past years. This could have potential effect on the accuracy of the information being given. However, this threat was minimized to its barest minimum by asking study participants to recall mostly in either the last one year or the last six months. The other limitation has to do with the tendency of respondents offering socially desirable responses. The use of filters in the questionnaire aided in checking any inconsistencies. Additionally, through the use of strict confidentiality and anonymity the participants freely agreed to provide accurate responses.

\section{Author's Contribution}

The paper conceptualization, design, results interpretation and manuscript writing was done by Appiah S. C. Y and Dapaah J. M. The design, manuscript review and final approval were done by Badu E. and Obeng B. All collaborated in interpretation of the data and preparing the manuscript. All authors have read and approved the final manuscript

\section{Conflict of Interest}

The authors' declare no conflict of interest.

\section{References}

[1] Hessburg, L., Awusabo-Asare, K., Kumi-Kyereme, A., Nerquaye-Tetteh, J.O., Yankey, F., Biddlecom, A. and CroceGalis, M. (2007) Protecting the Next Generation in Ghana: New Evidence on Adolescent Sexual and Reproductive Health Needs. Guttmacher Institute, New York.

[2] Katz, K. and Naré, C. (2002) Reproductive Health Knowledge and Use of Services among Young Adults in Dakar, Senegal. Journal of Biosocial Science, 34, 215-231. http://dx.doi.org/10.1017/S0021932002002158

[3] Erulkar, A.S., Ettyang, L.I., Onoka, C., Nyagah, F.K. and Muyonga, A. (2004) Behavior Change Evaluation of a Culturally Consistent Reproductive Health Program for Young Kenyans. International Family Planning Perspectives, 30, 58-67. http://dx.doi.org/10.1363/3005804

[4] Erulkar, A.S., Onoka, C.J. and Phiri, A. (2005) What Is Youth-Friendly? Adolescents' Preferences for Reproductive Health Services in Kenya and Zimbabwe. African Journal of Reproductive Health, 9, 51-58. http://dx.doi.org/10.2307/3583411

[5] Pande, R., Kurz, K., Walia, S., MacQuarrie, K. and Jain, S. (2006) Improving the Reproductive Health of Married and Unmarried Youth in India: Evidence of Effectiveness and Costs from Community-Based Interventions. Final Report of the Adolescent Reproductive Health Program in India.

[6] Foss, A.M., Hossain, M., Vickerman, P.T. and Watts, C.H. (2007) A Systematic Review of Published Evidence on Intervention Impact on Condom Use in Sub-Saharan Africa and Asia. Sexually Transmitted Infections, 83, 510-516. http://dx.doi.org/10.1136/sti.2007.027144

[7] Ross, D.A. (2010) Behavioural Interventions to Reduce HIV Risk: What Works? AIDS, 24, S4-S14. http://dx.doi.org/10.1097/01.aids.0000390703.35642.89

[8] Michielsen, K., Chersich, M., Temmerman, M., Dooms, T. and Van Rossem, R. (2012) Nothing as Practical as a Good Theory? The Theoretical Basis of HIV Prevention Interventions for Young People in Sub-Saharan Africa: A Systematic Review. AIDS Research and Treatment, 2012, Article ID: 345327. http://dx.doi.org/10.1155/2012/345327

[9] Chirwa, A.S. and Kudzala, A.C. (2001) Report on Assessment of Youth Friendly Health Services in Malawi National Youth Council of Malawi Lilongwe.

[10] Bond, K. (2004) Key Issues in the Implementation of Programs for Adolescent Sexual and Reproductive Health. World Health Organization, Geneva.

[11] Liu, Z., Zhu, M., Dib, H.H., Li, Z., Shi, S. and Wang, Z. (2011) RH Knowledge and Service Utilization among Unmarried Rural-to-Urban Migrants in Three Major Cities, China. BMC Public Health, 11, 74. http://dx.doi.org/10.1186/1471-2458-11-74

[12] Senderowitz, J. (1999) Making Reproductive Health Services Youth Friendly. A FOCUS on Young Adults 1201 Connecticut Avenue NW, Suite 501 Washington DC.

[13] Johns Hopkins Center for Communication Programs (1998) Reaching Young People Worldwide: Lessons Learned from Communication Projects, 1986-1995. Working Paper No. 2, Johns Hopkins Center for Communication Programs/ Population Communication Services/Population Information Program, Baltimore.

[14] Brindis, C. and Davis, L. (1998) Improving Contraceptive Access for Teens. Communities Responding to the Chal- 
lenge of Adolescent Pregnancy Prevention, 4.

[15] Townsend, J.W. (1987) Sex Education and Family Planning Services for Young Adults: Urban Strategies in Mexico. Studies in Family Planning, 18, 103-108. http://dx.doi.org/10.2307/1966701

[16] Zabin, L.S. and Clark, S.D. (1983) Institutional Factors Affecting Teenagers' Choice and Reasons for Delay in Attending a Family Planning Clinic. Family Planning Perspectives, 15, 25-29. http://dx.doi.org/10.2307/2134537

[17] Vadies, E. and Clark, J. (1988) [Comprehensive Adolescent Fertility Project in Jamaica]. Boletin de la Oficina Sanitaria Panamericana, 105, 359-370.

[18] Barker, G. (1994) Iniciativa de Evaluación de Programas de Salud Reproductiva de Adolescentes: ConfrontandoNuevos Desáfiospara el Siglo 21. Documento de discussion preparadopara la reunión de planeamiento en la Ciudad de Mexico, 20-21.

[19] Senderowitz, J. and Kirby, D. (2006) Standards for Curriculum-Based Reproductive Health and HIV Education Programs. Family Health International/YouthNet, Arlington.

[20] Appiah, S.C.Y., Badu, E., Dapaah, J.M., Harriet, T. and Abubakar, M. (2015) Youth Friendliness of Sexual and Reproductive Health Service Delivery and Reproductive Health Service Utilization in Ghana. International Journal of Innovation and Applied Studies, 10, 716-725.

[21] Okonofua, F., Coplan, P., Collins, S., Oronsaye, F., Ogunsakin, D., Ogonor, J.T., Kaufman, K.J. and Heggenhougen, K. (2003) Impact of an Intervention to Improve Treatment-Seeking Behaviour and Prevent Sexually Transmitted Diseases among Nigerian Youths. International Journal of Infectious Disease, 7, 61-73. http://dx.doi.org/10.1016/S1201-9712(03)90044-0

[22] Magnani, R.J., Gaffikin, L., de Aquino, E.M., Seiber, W.E., Almeida, M.C. and Lipovsek, V. (2001) Impact of an Integrated Adolescent Reproductive Health Program in Brazil. Studies in Family Planning, 32, 230-243. http://dx.doi.org/10.1111/j.1728-4465.2001.00230.x

[23] Michielsen, K. (2013) Limited Effectiveness of HIV Prevention for Young People in Sub-Saharan Africa: Studying the Role of Intervention and Evaluation. Facts, Views \& Vision in ObGyn, 5, 196-208.

[24] Kirby, D., Short, L., Collins, J., Rugg, D., Kolbe, L., Howard, M., Miller, B., Sonenstein, F. and Zabin, L.S. (1994) School-Based Programs to Reduce Sexual Risk Behaviors: A Review of Effectiveness. Public Health Reports, 109, 339-360.

[25] James, S., Reddy, S.P., Taylor, M. and Jinabhai, C.C. (2004) Young People, HIV/AIDS/STIs and Sexuality in South Africa: The Gap between Awareness and Behaviour. Acta Paediatrica, 93, 264-269. http://dx.doi.org/10.1111/j.1651-2227.2004.tb00718.x

[26] Odu, O.O., Asekun-Olarinmoye, E.O., Bamidele, J.O., Egbewale, B.E., Amusan, O.A. and Olowu, A.O. (2008) Knowledge, Attitudes to HIV/AIDS and Sexual Behaviour of Students in a Tertiary Institution in South-Western Nigeria. European Journal of Contraception and Reproductive Health Care, 13, 90-96.

[27] Askew, I., Chege, J., Njue, C. and Radeny, C. (2004) A Multi-Sectoral Approach to Providing Reproductive Health Information and Services to Young People in Western Kenya: Kenya Adolescent Reproductive Health Project.

[28] Deperthes, B.D., Meheus, A., O’Reilly, K. and Broutet, N. (2004) Maternal and Congenital Syphilis Programmes: Case Studies in Bolivia, Kenya and South Africa. Bulletin of the World Health Organization, 82, 410-416.

[29] Mugisha, J.F., Nyombi, J., Obare, F., Evelia, H. and Nyinkavu, H. (2008) Sexual and Reproductive Health Needs of Adolescents Perinatally Infected with HIV in Uganda. Population Council.

[30] Askew, I. and Berer, M. (2003) The Contribution of Sexual and Reproductive Health Services to the Fight against HIV/AIDS: A Review. Reproductive Health Matters, 11, 51-73. http://dx.doi.org/10.1016/S0968-8080(03)22101-7

[31] Bhuiya, I.U., Rob, A.H., Chowdhury, L., Rahman, N., Haque, S., Adamchak, R. and Khan, M.E. (2004) Improving Reproductive Health of Adolescents in Bangladesh. FRONTIERS Final Report, Population Council, Washington DC.

[32] Diop, N.J. and Nafissatou, J. (2004) Improving Reproductive Health of Adolescents in Senegal. FRONTIERS Final Report, Population Council, Washington DC.

[33] Vernon, R. and Dura, M. (2004) Improving the Reproductive Health of Youth in Mexico. FRONTIERS Final Report, Population Council, Washington DC.

[34] Michielsen, K., Chersich, M., Temmerman, M., Dooms, T. and Van Rossem, R. (2012) Nothing as Practical as a Good Theory? The Theoretical Basis of HIV Prevention Interventions for Young People in Sub-Saharan Africa: A Systematic Review. AIDS Research and Treatment, 2012, Article ID: 345327. http://dx.doi.org/10.1155/2012/345327

[35] Neukom, J. and Ashford, L. (2003) Changing Youth Behavior through Social Marketing. Program Experiences and Research Findings from Cameroon, Madagascar, and Rwanda, Population Services International and Population Reference Bureau, Washington DC.

[36] Moyo, I., Bond, K., Williams, T. and Mueller, L. (2000) Reproductive Health Antecedents, Attitudes, and Practices 
among Youth in Gweru, Zimbabwe. Pathfinder International, FOCUS on Young Adults, Washington DC.

[37] Speizer, I.S., Magnani, R.J. and Colvin, C.E. (2003) The Effectiveness of Adolescent Reproductive Health Interventions in Developing Countries: A Review of the Evidence. Journal of Adolescent Health, 33, 324-348. http://dx.doi.org/10.1016/S1054-139X(02)00535-9

[38] Family Health International (2006) YouthNet End of Program Report. Taking Action: Recommendations and Resources. Arlington.

[39] Ghana Statistical Services (2012) Population \& Housing Census: Summary Report of Final Results 2010. Ghana Statistical Service Accra, Ghana.

[40] Population Council (1999) Peer Education and HIV/AIDS: Past Experience and Future Direction. Horizons Project.

[41] Godia, P. (2010) Youth Friendly Sexual and Reproductive Health Service Provision in Kenya: What Is the Best Model? $\mathrm{MOH}$, Nairobi.

[42] Pathfinder International (2005) Youth-Friendly Services: Ghana End of Program Evaluation Report. Pathfinder International, USA.

\section{Abbreviations}

SRHS: sexual and reproductive health services;

FBSRHS: facility-based sexual and reproductive health service;

YFSRHS: youth friendly sexual and reproductive health services. 